\title{
Representações sociais de usuários sobre o Programa Saúde da Família
}

\author{
The social representations of the users about the Family Health Program
}

Trata-se de um estudo de caso com abordagem qualitativa, fundamentado na Teoria das Representações Sociais, com o objetivo de apreender as representações sociais de usuários sobre o Programa Saúde da Família. Os sujeitos da pesquisa foram sete usuários, sendo dois homens e cinco mulheres, com a média de idade de 70 anos, moradores, há aproximadamente dez anos, da área de abrangência de uma Unidade Básica de Belo Horizonte, localizada no distrito Noroeste. Realizou-se entrevista aberta com base na seguinte questão norteadora: "o que você entende sobre o Programa Saúde da Família?". As entrevistas foram encerradas no momento da saturação dos dados. Utilizou-se a análise de discurso para a interpretação dos dados. Fez-se a leitura sistematizada das entrevistas para definição do corpus e apreensão das representações dos usuários sobre o Programa Saúde da Família. Os dados foram organizados em duas categorias: 1 - no tempo em que acesso significava espera e falta; 2 - novas formas de fazer saúde, novas formas de representá-la. A primeira refere-se às representações sociais da atenção à saúde no período anterior à implantação do Programa em Belo Horizonte, enquanto a segunda mostra as representações no momento atual. Com base nessas categorias, percebe-se que há mudanças reconhecidas no discurso dos usuários, com outro olhar sobre as ações desenvolvidas pelos profissionais na Unidade Básica. As representações dos usuários sobre o Programa Saúde da Família não são definidas pelo reconhecimento do nome ou da sigla estabelecida pelo Setor Saúde e por seus trabalhadores, mas por aproximações e noções construídas no cotidiano das relações que vivenciam quando procuram atendimento. Os usuários percebem o momento de transição que o Setor Saúde vivencia, o que reflete sobre novas formas de representação do Programa apesar de haver resquícios, em sua memória, do atendimento que recebiam antes da implantação do atual modelo. Destacam a garantia de acesso ao Serviço com o término das filas, a construção de vínculos com os profissionais que os atendem, além de identificarem a Unidade Básica de Saúde como espaço social onde podem desenvolver atividades de promoção da saúde. Espera-se que este estudo proporcione reflexões, por parte de profissionais e gestores, sobre a importância de conhecermos os valores e crenças dos usuários quanto à organização do Serviço e sobre a parceria com os usuários para que os princípios da estratégia de Saúde da Família sejam alcançados integralmente.

\author{
Ana Paula Azevedo Hemmi \\ Dissertação de Mestrado (2008) \\ Escola de Enfermagem, Universidade Federal de \\ Minas Gerais, Belo Horizonte \\ anahemmi@gmail.com
}

Palavras-chave: Saúde da família. Sistema Único de Saúde. Representações sociais. Participação comunitária. Acesso aos serviços de saúde.

Keywords: Family health. National Health Programs. Social representations. Consumer participation. Health services accessibility.

Palabras Clave: Programa de Salud Familiar. Sistema Básico de la Salud. Representaciones sociales. Participación de la comunidad. Acceso a los servicios de la salud.

Texto na íntegra disponível em: http://www.enf.ufmg.br/ mestrado/dissertacoes/AnaPaulaHemmi.pdf. 